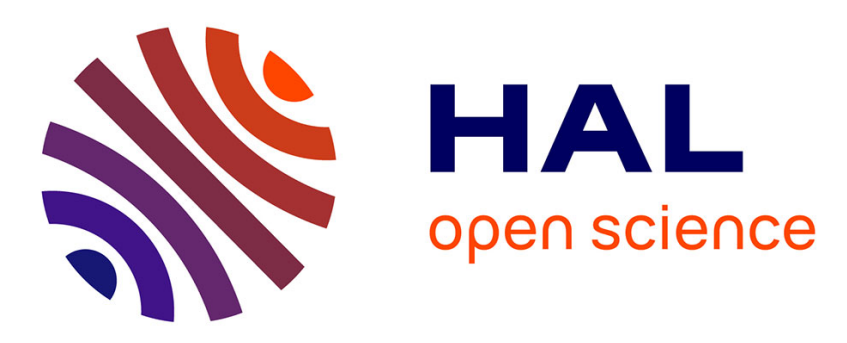

\title{
Texture and Genesis of Polycrystalline Varieties of Diamond Based on Phase-Contrast and Diffraction Contrast Tomography
}

A. Shiryaev, F. V Kaminsky, Wolfgang Ludwig, D. A Zolotov, A. Buzmakov, S. V Titkov

\section{To cite this version:}

A. Shiryaev, F. V Kaminsky, Wolfgang Ludwig, D. A Zolotov, A. Buzmakov, et al.. Texture and Genesis of Polycrystalline Varieties of Diamond Based on Phase-Contrast and Diffraction Contrast Tomography. Geochemistry International / Geokhimiya, 2019, 57 (9), pp.1015-1023. 10.1134/S0016702919090106 . hal-02404548

\author{
HAL Id: hal-02404548 \\ https://hal.science/hal-02404548
}

Submitted on 16 Dec 2019

HAL is a multi-disciplinary open access archive for the deposit and dissemination of scientific research documents, whether they are published or not. The documents may come from teaching and research institutions in France or abroad, or from public or private research centers.
L'archive ouverte pluridisciplinaire HAL, est destinée au dépôt et à la diffusion de documents scientifiques de niveau recherche, publiés ou non, émanant des établissements d'enseignement et de recherche français ou étrangers, des laboratoires publics ou privés. 


\title{
Texture and genesis of polycrystalline varieties of diamond based on phase-contrast and diffraction contrast tomography
}

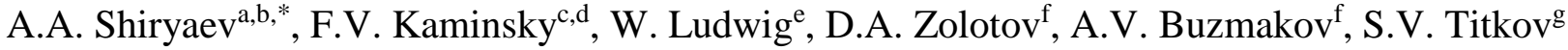 \\ ${ }^{a}$ Frumkin Institute of Physical chemistry and electrochemistry RAS, Leninsky pr. 31, korp. 4, \\ Moscow 119071, Russia \\ ${ }^{b}$ Institute of Geology of Ore deposits, Petrography, Mineralogy and Geochemistry RAS, \\ Staromonetny per. 35, 119017 Moscow, Russia \\ ${ }^{c}$ Vernadsky Institute of Geochemistry and Analytical Chemistry RAS, Moscow, Russia \\ ${ }^{\mathrm{d}}$ KM Diamond Exploration Ltd., West Vancouver, BC, V7S 3J1, Canada \\ ${ }^{\text {e }}$ ESRF, Grenoble, France \\ ${ }^{\mathrm{f}}$ Shubnikov Institute of Crystallography FSRC "Crystallography and Photonics" RAS \\ * - Corresponding author. Email: shiryaev@ phyche.ac.ru AND a_shiryaev@ mail.ru; \\ Phone: +74959554664
}

\begin{abstract}
Structural peculiarities of several types of cryptocrystalline diamond varieties: carbonado, impact-related yakutite and cryptocrystalline diamond aggregates from kimberlite were studied using Infrared spectroscopy, X-ray diffraction contrast (DCT - Diffraction Contrast Tomography) and phase contrast tomography (PCT). It is shown that the porosity of the carbonado and kimberlitic cryptocrystalline aggregates is similar being in range of 5-10 vol\%, possibly indicating similar formation mechanism(s), whereas that of yakutite is essentially zero. Crystallographic texture is observed for some carbonado samples. It is suggested that at least partially the texture is explained by deformation-related bands. Infrared spectroscopy reveals presence of hydrous and, probably, of hydrocarbon species in carbonado.
\end{abstract}

Keywords: carbonado; yakutite; cryptocrystalline diamond; texture; phase-contrast tomography; Diffraction-contrast tomography

\section{INTRODUCTION}

Several types of natural polycrystalline diamonds are known (Jeynes, 1978, Sunagawa 1984; Orlov 1987). They span a range from simple aggregates such as boart and diamondite with 
various grain sizes and whose formation mechanism is likely similar to that of single crystals, to cryptocrystalline varieties such as carbonado and yakutite. Carbonado is a very peculiar and enigmatic variety of natural diamond. It is a black or dark-brown, cryptocrystalline, porous diamond aggregate (Kaminsky, 1994) of undetermined origin. Morphological and mineralogical properties of carbonado differ considerably from those of diamond single crystals and polycrystalline aggregates related to kimberlites and lamproites. Primary source(s) of carbonado remains elusive; they are found only in placer deposits in Brazil, Central African Republic, Russian Far East, and possibly Venezuela (Kaminsky, 1994). One of the peculiarities of carbonado, in addition to mineral inclusions typical for crustal conditions, is its microstructure: it is composed of diamond micro-grains (crystallites) with sizes ranging from $0.5-1$ to several tens of micrometers (Magee and Taylor, 1999; De et al., 2001; Petrovsky et al., 2010). Grain boundaries between crystallites often form zigzag-like pattern, and overall have some similarities with sintered diamonds. In the same time, some of fine-crystalline polycrystals (fine-grained and cryptocrystalline boart, diamondite) from kimberlite pipes (Jeynes 1978; Kaminskiy et al. 1981; Titkov et al., 2001; Spetsius and Taylor 2008; Sobolev et al. 2016), from Avacha volcano, Kamchatka (Kaminsky et al., 2016) and yakutite - a Popigai crater impact ejecta (Orlov and Kaminskiy 1981; Titkov et al., 2004; Yelisseyev et al., 2016) - exhibit features similar to classical carbonado from Brazil and Central Africa. Contradictory observations, such as coexistence of highly reduced and oxidized mineral inclusions, have given rise to numerous hypotheses concerning the genesis of carbonado, ranging from deep mantle horizons (Nadolinny et al., 2003; Petrovsky et al., 2010) to near-surface conditions (Kaminsky, 1987).

Studies of carbonado structure are numerous and were performed using transmission electron microscopy (TEM) and electron backscattered diffraction (EBSD) (Trueb and Butterman 1969; Moriyoshi et al. 1983; De et al. 1998; Chen and Van Tendeloo 1999; Sautter et al., 2011; Ishibashi et al., 2012; Kaminsky et al., 2013), X-ray absorption tomography (Ketcham and Koeberl, 2013), neutron diffraction and transmission Kikuchi diffraction analysis (Piazolo et al., 2016). EBSD demonstrated that the grain size distribution in several studied carbonado samples is indeed broad $(1-55 \mu \mathrm{m})$, but is largely unimodal with a peak around 5-15 $\mu \mathrm{m}$. In the same time, absence of a clear peak in the grain size distribution was found in Ishibashi et al., (2016, and references therein). Neutron diffraction allows investigation of bulk samples and provides statistics for thousands of grains against hundreds of grains in EBSD case, but due to lower fluence, is limited to relatively large grains. Both EBSD and neutron diffraction confirmed lack of crystallographic preferred orientation of crystallites in carbonado, although most grains exhibit locally significant internal plastic deformation (Piazolo et al., 2016), confirming earlier TEM results (Trueb and Butterman 1969; De et al. 1998). On the other hand, X-ray absorption 
tomography demonstrated a preferred orientation of mineral inclusions and pores in a carbonado specimen (Ketcham and Koeberl, 2013). Crystallographic texture of yakutite and mutual crystallographic orientation of diamond and its hexagonal polytype - lonsdaleite - were addressed by X-ray diffraction in considerable detail (Kharlashina and Naletov, 1991; Sokhor and Futergendler, 1975, respectively).

Despite all these works, unambiguous scenario of carbonado formation is still lacking. In this contribution we characterize structural peculiarities of several cryptocrystalline diamond varieties: carbonado from Central African Republic, impact-related yakutite, and cryptocrystalline diamond aggregates from Yakutia using relatively novel techniques of diffraction contrast tomography (DCT) and phase contrast tomography (PCT). In addition, infrared (IR) spectroscopy in reflection and Attenuated Total Reflection (ATR) modes were used to extract information on nitrogen aggregation state and some inclusions. On this basis, we attempt to constrain mechanisms of formation of these polycrystalline varieties of diamond.

\section{SAMPLES AND TECHNIQUES}

\section{Samples}

The samples analyzed in this work are three Central-African grains (CAR-1, 2 and 3) collected from Ubangi River placer deposit, which were studied by Kaminsky et al. (2013) and Piazolo et al. (2016). They contain syngenetic inclusions of apatite, sulfides $\mathrm{FeS}$ and $\mathrm{FeS}_{2}, \mathrm{SiO}_{2}$, $\mathrm{TiO}_{2}$, Si-Ti-Al-Mg-Fe-Ca-K-O silicate, iron oxide, Ca-Mg-Sr carbonate, and various quench phases. According to Kaminsky et al. (2013) such inclusion suites might indicate crustal origin.

The yakutite sample was collected in a contemporary placer of the Olenyok River in Yakutia. It is a dark-gray irregular pebble with rounded surfaces, $\sim 9 \mathrm{~mm}$ in size. The studied sample contains approximately $25-30 \%$ of lonsdaleite admixture and has significantly smaller crystallite sizes $(0.1-1 \mu \mathrm{m})$ than carbonado.

In addition, three samples of cryptocrystalline diamond aggregates from Yakutian kimberlites previously characterised by Titkov et al. (2001) were also investigated. These samples contain micron-size inclusions of native $\mathrm{Fe}, \mathrm{Cr}, \mathrm{Ni}$, rutile, sphalerite, pentlandite, muscovite, zircon-xenotime solid solutions and also epigenetic anatase, florensite, kaolinite and goetite. Debye rings in electron diffraction patterns indicate that significant fraction of diamond grains in these samples were below $1 \mu \mathrm{m}$. REE patterns determined by bulk neutron activation analysis correspond to typical kimberlites. Electron Paramagnetic resonance shows presence of the P1 (single substitutional nitrogen or the C-defect) and the W15 (single nitrogen with a vacancy, i.e., $\mathrm{NV}^{-}$) paramagnetic centers. 


\section{Methods}

Infrared (IR) spectroscopy of micro- and nanocrystalline materials is often complicated by strong light scattering on grain boundaries and other imperfections, if characteristic distance between the defects becomes comparable with the wavelength of the probing radiation. Most IR studies of diamond concentrate on bands corresponding to the diamond lattice $(\sim 5 \mu \mathrm{m})$ and to nitrogen defects $(7-20 \mu \mathrm{m})$. As indicated above, an average carbonado sample contains grains of widely different sizes, but significant fraction may be smaller than these values. In addition, many carbonado samples contain numerous strongly absorbing inclusions. To overcome some of the difficulties, we have employed Attenuated Total Reflections (ATR) technique for investigation of the carbonado. Application of the ATR spectroscopy requires very good physical contact between the sample surface and the ATR crystal. IR spectra were acquired using Ge crystal with a tip diameter of 150 microns for two samples, however the acquisition was unsuccessful for the third one. IR spectra of polycrystalline diamonds were recorded using Diffuse reflectance attachment, the samples were placed on gold mirrors.

\section{$X$-ray Diffraction contrast tomography (DCT) and phase contrast tomography (PCT)} were performed at the ID11 beamline of European Synchrotron Radiation Source. The DCT approach is based on acquisition of large number of 2D diffraction patterns separated by small angular distance, identification of grains, matching of Friedel pairs for every discernible grain and subsequent reconstruction of their shape and orientation. For detailed reviews of experimental protocol and evaluation procedure see Ludwig et al. (2009) and Reischig et al. (2013).

Despite relatively high energy of $\mathrm{X}$-rays $(40 \mathrm{keV})$ small lattice parameter of diamond required acquisition of the diffraction patterns in wide angular range which forced us to use small sample-to-detector distance. Irregular shape of the samples further complicated the experiment and we had to limit the investigated volume to apexes of the samples.

Phase contrast tomography differs from more widely employed absorption tomography in significantly higher sensitivity to grain boundaries, cracks etc. The pixel size of Freelon camera employed in the current study was $0.7 \mu \mathrm{m}$. Whole samples were studied.

Since extraction of porosity from the tomographic images can be performed by various algorithms with somewhat different results, we provide a brief description of the procedure used by us (see also Soille, 1999). The treatment was performed using MATLAB Image Processing Toolbox. The first operation requires segmentation of every slice. To achieve this on the first step binarisation of the slices was performed. The imfill function was employed to equalize voids 
inside the sample with the background. Filtration with the imerode function with circular size of 2 pixels was employed to reduce noise. To select the total volume of the object smoothing using morphological closing operation was performed employing 10-pixel circular disk in the imerode. Remaining unfilled domains were again treated using the imfill function. The mask obtained using this approach is a binary image, which allows robust calculation of the total volume.

Similar procedure was used to separate inclusions of foreign phases and filled pores, but on the first step adaptive threshold filtration (function adaptthresh) and subsequent inversion of the binary mask were employed.

The approach described above was applied to all tomographic slices, which allowed extracting relative fractions of the pores and inclusions for every slice. One-dimensional median filtration was used for smoothing.

\section{RESULTS}

\section{Infrared spectroscopy}

FTIR spectra of the carbonado samples are shown in Fig. 1; for every sample, several spots were analysed. No bands related to diamond lattice or to nitrogen defects are observed. However, this is not surprising due to the micro-nanocrystalline nature of carbonado and such situation was earlier encountered both for natural carbonado (e.g., Ishibashi et al., 2012) and for several types of synthetic analogues (Shiryaev et al., 2006). In one-phonon region of the spectra broad peaks with maxima at 900, 1000 and $1030 \mathrm{~cm}^{-1}$, presumably due to inclusions, are observed. Several other prominent features are present in all spectra: a strong doublet at 2920 $\mathrm{cm}^{-1}$ and broad bands centered at 1650 and $3200-3600 \mathrm{~cm}^{-1}$. The first doublet is due to $\mathrm{C}-\mathrm{H}$ bonds in methylene groups and might represent contamination, which has survived chemical cleaning preceding the IR study. However, keeping in mind presence of hydrocarbons in carbonado (Kaminsky et al., 1985) these bands may be related to such species. Two other bands are clearly related to vibrations of $\mathrm{OH}$-groups and molecular water. Observation of these bands is in line with previous reports (Magee and Taylor, 1999; Ishibashi et al., 2012) and is explained by presence of hydrous minerals and fluid microinclusions.

The polycrystalline diamond aggregates from Yakutian kimberlites were not polished and were investigated in diffuse reflectance mode. Their spectra differ from those of carbonado by presence of obvious diamond lattice bands and nitrogen defects represented by dominating Cdefects with some admixture of A-defects. Such spectra are typical for diamonds subjected to moderate annealing. Strong absorption bands due to water and $\mathrm{OH}$-species are also present. 


\section{Phase contrast tomography}

Representative tomographic slices from the studied samples are shown in Fig. 2. One can immediately recognize differences between the impact-related yakutite specimen from one side and carbonado and cryptocrystalline diamond aggregate. The yakutite contains only several cracks and is a dense material otherwise. We note here that examination of flaky impact-related diamonds from the Popigai crater itself (unpublished) also showed homogeneous internal structure. In the same time, the cryptocrystalline samples from Central Africa and Yakutia are clearly heterogeneous and contain both pores and inclusions. Some inclusions fill pores completely, some preserve open space. The inclusions could be connected to cracks, but in many cases they are fully surrounded by diamond matrix (see also Ketcham and Koeberl, 2013). The carbonado samples from African placers and cryptocrystalline aggregates from Yakutian kimberlites show significant similarities in geometry, sizes and spatial distribution of the pores. The only marked difference is significantly lower concentration of inclusions in the latter case.

Image analysis of the slices was performed in order to estimate the relative pore fraction (Fig. 3), see Methods section for details. For some samples the contrast matrix/pore was too weak for reliable analysis, therefore Figure 3 shows results only for samples CAR2 and diamondites. The fraction of the pores is approx. 5-7\% and all four samples are qualitatively similar.

\section{X-ray diffraction contrast tomography}

The studied yakutite specimen differs from the other samples by showing pronounced texture (see also Kharlashina and Naletov, 1991) and is not analysed further. One of the carbonado samples and all cryptocrystalline aggregates from Yakutia showed almost continuous Debye rings indicating very small grain sizes. Unfortunately, in such cases analysis of individual grains becomes impossible. Eventually this task can be solved by using a smaller X-ray beam and by scanning the sample. A 3D visualization of grains in two carbonado sample is shown in Fig. 4.

Projections of Orientation Distribution Functions (ODF) on several crystallographic planes - pole figures - are shown in Fig. 5. For CAR-1 624 grains were analysed, for CAR-2 1100. In addition only the grains smaller than several arbitrary size thresholds were also plotted, but resulting pole figures are very similar to those obtained for the complete grains set. Examination of the pole figures clearly show existence of a preferential orientation of diamond grains in [111]. A smaller grain fraction is oriented in [110]. Examination of spatial arrangement 
of the [110]-oriented grains in individual slices show that at least in some cases these grains form bands (Fig. 6).

\section{DISCUSSION}

This work presents new results on structure of several types of polycrystalline diamonds with presumably different formation mechanisms. The impact-related sample - yakutite - clearly stands off the row possessing very dense structure without obvious inclusions. Clear differences between structures of natural and synthetic impact diamonds and carbonado rule out exotic but still popular hypotheses relating carbonado to meteorites and extraterrestrial bodies.

The principal new observation on carbonado is clearly revealed [111] texture in two samples, which were previously studied using EBSD (Kaminsky et al., 2013) and neutron diffraction (Piazolo et al, 2016). The difference between all these studies likely stems from significantly higher statistics of the current study (up to 1000 grains) and acquisition of grainspecific three-dimensional information. We note here that our investigation is limited to grains exceeding certain size, namely, larger than 3-4 pixels, i.e. 2-3 microns, since shape of smaller grains can not be resolved in the current experiment.

Textured polycrystals can be produced by several independent mechanisms such as:

1) Crystallization process in which faceted crystallites are precipitated in ordered arrangement relative to each other.

2) Recrystallisation process leading to preferential growth of some grains in the expense of heavily strained ones.

3) Deformation leading to formation of preferential orientation.

Of course, these mechanisms are not mutually contradictory and may operate simultaneously or in sequence. Lets consider these mechanisms in detail.

A crystallisation process may produce ordered aggregates in several circumstances and the simplest one is an ordered settling or formation of individual grains possessing similar morphology. Crystallization of carbonado at slowly changing carbon supersaturation was suggested, for example, by Petrovsky et al. (2010) on the basis of gradual changes in morphology and surface features of large ( $>5$ microns) diamond grains.

The recrystallisation process was suggested to operate in carbonado and diamondite in order to explain fine details of internal structure (Rubanova et al., 2012; Piazolo et al., 2016), in particular, serrated grain boundaries. Whereas this approach adequately describes some features, it implies extensive atomic diffusion. It is known, however, that self-diffusion in diamond is extremely sluggish (Koga et al., 2003) and even fine compositional zoning remains largely intact 
at mantle temperatures for time scales of several billion years. Infra-red data for carbonado suggest that the annealing of carbonado was insignificant both in time and temperature, since $\mathrm{N}$ aggregation state is low (Kagi and Fukura 2008; this work). Moreover, in deformation processes when two orthogonal slip systems operate (pure shear), serration of grains is not uncommon, thus obviating the recrystallisation process. We note also that in case of submicron grains diamond can be reversibly deformed elastically without cracking or generation of dislocations (Banerjee et al., 2018); this mechanism might also operate in some grains during the deformation of the carbonado specimen.

Nevertheless, these contradictions could be at least partially resolved if extensive plastic deformation is present. At high temperatures diamond can be deformed plastically and under confinement pressure of $6 \mathrm{GPa}$ the plastic behavior is observed already at $900{ }^{\circ} \mathrm{C}(\mathrm{DeV}$ ries, 1975). This process is widespread in nature, manifested, for example, in presence of birefringence in absolute majority of natural diamonds. In the same time, recrystallisation kinetics of (sub)microscopic grains strongly depend on surface diffusion, which is generally faster than of the bulk. Whereas the nitrogen aggregation is largely driven by relaxation of local strain in diamond lattice on scale of several tens of lattice parameters and formation of a $\mathrm{N}$ pair (the A-defect) greatly reduce the strain (Briddon and Jones, 1993), the mass flow of carbon atoms in a significant strain field may be well-pronounced as demonstrated by bending of a single crystal diamond plate for 8 degrees (Evans and Wild, 1965). In addition, plastic deformation introduces vacancies, which promote atomic diffusion and are detected as NV/W15 defects in photoluminescence/EPR spectra of carbonado (of course some vacancies are also produced by irradiation from radioactive inclusions) (Klyuev et al., 1978; Petrovsky et al., 2010; Titkov et al., 2001).

It is interesting to note that in most cases deformation of a polycrystal leads to rotation of grains. In view of this our observation that the [110]-oriented grains appear to be distributed not completely randomly, but instead they likely form kind of bands (fig. 6).

Another interesting result of the current study is observation of close similarities between porous structure of sensu stricto carbonado and kimberlitic cryptocrystalline diamond aggregates. We note here that extensive porosity does not contradict to high formation pressures: for example, bulk poly- and nanocrystalline diamonds with abundant pores filled with water and other materials were obtained at pressures of up to $25 \mathrm{GPa}$ and temperatures in excess of $2000{ }^{\circ} \mathrm{C}$ (Shiryaev et al., 2006). Whereas the "real" carbonado differs from the cryptocrystalline aggregates from kimberlites in appearance and composition of inclusions, these variations might be explained assuming much older ages of Brazilian and African carbonadoes and complex 
history of their secondary alteration. Indeed, already the inclusions in Brazilian carbonado are dated as $3 \mathrm{Ga}$ (Sano et al., 2002), indicating that the carbonado matrix itself should be older.

Results of the current study are in line with several previous studies where carbonado formation was described as growth of individual diamond crystallites in confined environment at high carbon supersaturation, their sintering and/or intergrowth and subsequent deformation at a later stage (Burgess et al., 1998; De et al., 2001; DeVries, 1973; Magee and Taylor, 1998; Petrovsky et al., 2010; Piazolo et al., 2016). In some works presence of two (and even three) populations of diamond crystallites in a single carbonado specimen was suggested (Magee and Taylor, 1998; De et al., 2001; Rondeau et al 2008), although temporal and genetic relationships between them remain unspecified. In other cases, a single population is inferred from grain size distribution (Ishibashi et al., 2016; Kaminsky et al., 2013). It is very likely that both cases are possible, and the two extreme cases ("multiple" vs "single" population of grains) represent various steps of one general process, which presumably operated at mantle conditions. Even isotopic and chemical (amount of $\mathrm{N}$ ) heterogeneity of diamond grains in individual carbonado samples can be explained in this framework, since surface properties of different growth sectors (Zedgenizov et al., 2006; Reutsky et al., 2017a) and variations in growth rate (Reutsky et al., 2012, 2017b) may lead to noticeable variations of $\mathrm{C}, \mathrm{N}$ isotopic composition and $\mathrm{N}$ content even within a single diamond crystal.

\section{CONCLUSIONS}

We present results of investigation of samples representing different types of poly- and cryptocrystalline diamond varieties using novel X-ray and spectroscopic techniques. The impactrelated diamond - yakutite - clearly differs from the carbonado and kimberlitic diamond aggregate, thus ruling out possibility of impact origin of the later diamond varieties. However, results for the carbonado and the kimberlitic cryptocrystalline aggregate are more difficult to compare. Whereas some of the features - such as porosity, are fairly similar, other properties, in particular grain size distribution and spectroscopically-active impurities, differ in a nonsystematic way. We show that the grain size distribution is not a very robust criterion to distinguish between the sensu stricto carbonado from CAR and carbonado-like samples from kimberlites.

Our study provides new evidence for deformation stage in history of carbonado, which is manifested in marked crystallographic texture of the studied samples.

Presence of significant amount of hydrous and possibly hydrocarbon species in carbonado and kimberlitic cryptocrystalline diamonds is inferred from infrared spectroscopy. 


\section{Acknowledgements}

This work was supported by the Ministry of Science and Higher Education of Russian Federation.

Part of analysis was performed within the State assignment FSRC «Crystallography and Photonics» RAS.

\section{References}

A. Banerjee, D. Bernoulli, H. Zhang, M.-F. Yuen, J. Liu, J. Dong, F. Ding, J. Lu, M. Dao, W. Zhang, Y. Lu, S. Suresh, "Ultralarge elastic deformation of nanoscale diamond", Science 360, 300-302 (2018).

P. Briddon, R. Jones, “Theory of impurities in diamond”, Physica B 185, 179-189 (1993).

R. Burgess, L. H. Johnson, D. P. Mattey, J. W. Harris and G. Turner, "He, Ar and C isotopes in coated and polycrystalline diamonds", Chem. Geol., 146 (3-4), 205-217 (1998).

J. H. Chen, G. van Tendeloo, "Microstructure of tough polycrystalline natural diamond", J Electron Microscopy 48 (2), 121-129 (1999).

S. De, P. J. Heaney, R. B. Hargraves, E. P. Vicenzi and P. T. Taylor, "Microstructural observations of polycrystalline diamond: a contribution to the carbonado conundrum", Earth Planet. Sci. Lett. 164 (3-4), 421-433 (1998).

S. De, P. J. Heaney, E. P. Vicenzi and J. Wang, "Chemical heterogeneity in carbonado, an enigmatic polycrystalline diamond”, Earth Planet. Sci. Lett. 185(3-4), 315-330 (2001).

R. C. DeVries, "Evidence for plastic deformation in the natural polycrystalline diamond, framesite", Mat. Res. Bull. 8, 733-742 (1973).

R. C. DeVries, "Plastic deformation and "work-hardening" of diamond", Mat. Res. Bull. 10, 1193-1200 (1975).

T. Evans T, R. K. Wild, "Plastic bending of diamond plates", Phil. Mag. 117(12), 479-486 (1965).

M. I. Sokhor, S. I. Futergendler, "X-ray diffraction study of cubic-diamond lonsdaleite formations", Soviet Phys. Crystallogr. 19(4), 471-473 (1975) (translated from: Kristallografiya, 1974, 19, 759-762).

H. Ishibashi, H. Kagi, H. Sakuai, H. Ohfuji, H. Sumino, "Hydrous fluid as the growth media of natural polycrystalline diamond, carbonado: implication from IR spectra and microtextural observations", Amer. Miner. 97, 1366-1372 (2012).

H. Ishibashi, H. Kagi, S. Odake, H. Ohfuji, H. Kitawaki, "Relationships between textural and photoluminescence spectral features of carbonado (natural polycrystalline diamond) and implications for its origin", Geochem. Intern. 54(10), 882-889 (2016).

C. Jeynes, "Natural polycrystalline diamond", Ind. Diam. Rev. 38, 14-23 (1978).

G. Johnson, A. King, M. G. Honnicke, J. Marrow, W. Ludwig, "X-ray diffraction contrast tomography: a novel technique for three-dimensional grain mapping of polycrystals. II. The combined case", J. Appl. Cryst. 41, 310-318 (2008).

H. Kagi, S. Fukura, "Infrared and Raman spectroscopic observations of Central African carbonado and implications for its origin”, Eur. J. Miner. 20(3), 387-393 (2008).

F. V. Kaminsky, "Origin of polycrystalline carbonado diamond aggregates", Doklady Earth Sci. 294, 122-123 (1987) (translated from Doklady Akademii Nauk SSSR 294(2), 439-440 (1987)).

F. V. Kaminsky (1994) "Carbonado and yakutite: properties and possible genesis". In: Proceedings of the Fifth International Kimberlite Conference, vol. 2. Diamonds: Characterization, Genesis and Exploration (Ed. by H.O.A. Meyer and O.H. Leonardos). Brazil, p. 136-143.

F. V. Kaminskiy, E. M. Galimov, Yu .S. Genshaft, I. N. Ivanovskaya, Yu. A. Klyuev, V. S. Rovsha, S. M. Sandomirskaya, V. I. Smirnov, "Bort with garnet from the Mir pipe, Yakutia”. Doklady Earth Sci. Section 256, 115-117 (1981) (Translated from: Doklady AN 
SSSR 256(3), 674-677).

F. V. Kaminskiy, I. I. Kulakova, A. I. Ogloblina, "Polycyclic aromatic hydrocarbons in carbonado and diamond", Dokl Earth Sci. Section, 283(4), 147-150 (1985) (Translated from: Doklady AN SSSR 283(4), 985-988).

F. V. Kaminsky, R. Wirth, L. Morales, "Internal texture and syngenetic inclusions in carbonado", Can. Miner. 51, 39-55 (2013).

F. V. Kaminsky, R. Wirth, L. P. Anikin, L. Morales, A. Schreiber, "Carbonado-like diamond from the Avacha active volcano in Kamchatka, Russia", Lithos 265, 222-236 (2016).

N. N. Kharlashina, A. M. Naletov, "Textures of natural lonsdaleite-bearing diamonds", Geochemistry international, 28(3), 98-102 (1991) (Translated from Geokhimiya (1990), 28:1179-1184).

Yu. A. Klyuev, V. I. Nepsha, N. I. Epishina, V. I. Smirnov, S. P. Plotnikova, B. I. Prokopchuk, F. V. Kaminskiy, "Distinctive features of natural polycrystalline diamonds", Sov Phys Doklady, 23, 370-372 (1978).

R. A. Ketcham, C. Koeberl, "New textural evidence on the origin of carbonado diamond: an example of 3-D petrography using X-ray computed tomography", Geosphere 9, 1336-1347 (2013).

K. T. Koga, J. A. van Orman, M. J. Walter, "Diffusive relaxation of carbon and nitrogen isotope heterogeneity in diamond: a new thermochronometer", Phys. Earth Planet. Inter. 139(1), 35-43 (2003).

W. Ludwig, P. Reischig, A. King, M. Herbig, E. M. Lauridsen, G. Johnson, T. J. Marrow, J. Y. Buffìre, "Three-dimensional grain mapping by x-ray diffraction contrast tomography and the use of Friedel pairs in diffraction data analysis", Rev. Sci. Instrum., 80(3), 033905 (2009).

C. W. Magee, W. R. Taylor, "Constrains from luminescence on the history and origin of carbonado", Proceedings of the VIIth Internat. Kimberlite Conference, vol. 2. Red Roof Design, Cape Town, p. 529-532 (1999).

Y. Moriyoshi, M. Kamo, N. Setaka, Y. Sato, "The microstructure of natural polycrystal diamond, carbonado, and ballas", J. Mater. Sci. 18 (1), 217-224 (1983).

V. A. Nadolinny, V. S. Shatsky, N. V. Sobolev, D. J. Twitchen, O. P. Yuryeva, I. A. Vasilevsky and V. N. Lebedev, "Observation and interpretation of paramagnetic defects in Brazilian and Central African carbonados", Amer. Miner. 88(1), 11-17 (2003).

Yu. L. Orlov (1987) Mineralogy of Diamond. John Wiley \& Sons, NY, 235 pp.

Yu. L. Orlov, F. V. Kaminskiy, "Carbonado with lonsdaleite, a new (eleventh) variety of polycrystalline diamond aggregate", Doklady Earth Sci. 259, 161-163 (1981) (Translated from: Doklady AN SSSR 1981, 259(2), 459-461).

V. A. Petrovsky, A. A. Shiryaev, V. P. Lyutoev, A. E. Sukharev, M. Martins, "Morphology and defects of diamond grains in carbonado: clues to carbonado genesis”, Eur. J. Miner. 22(1), 35-47 (2010).

S. Piazolo, F. V. Kaminsky, L. Evans, P. Trimby, V. Luzin, "Carbonado revisited: Insights from neutron diffraction analysis, high resolution orientation analysis and numerical simulations", Lithos 265, 244-256 (2016).

P. Reischig, A. King, L. Nervo, N. Viganó, Y. Guilhem, W. J. Palenstijn, K. J. Batenburg, M. Preuss and W. Ludwig, "Advances in X-ray diffraction contrast tomography: flexibility in the setup geometry and application to multiphase materials", J. Appl. Cryst., 46, 297-311 (2013).

V. N. Reutsky, Y. M. Borzdov, Y. N. Palyanov, "Effect of diamond growth rate on carbon isotope fractionation in Fe-Ni-C system", Diam. Relat. Mater. 21, 7-10 (2012).

V. N. Reutsky, P. Kowalski, Y. N. Palyanov, M. Wiedenbeck, "Experimental and theoretical evidence for surface-induced carbon and nitrogen fractionation during diamond crystallization at high temperatures and high pressures", Crystals, 7(7), 190 (14 pp.) (2017a). 
V. N. Reutsky, A. A. Shiryaev, S. V. Titkov, M. Wiedenbeck, N. N. Zudina, "Evidence for large scale fractionation of carbon isotopes and of nitrogen impurity during crystallization of gem quality cubic diamonds from placers of North Yakutia”, Geochem. Intern. 55(11), 988-999 (2017b).

B. Rondeau, V. Sautter, J. Barjon, "New columnar texture of carbonado: cathodoluminescence study", Diam. Relat. Mater. 17(11), 1897-1901 (2008).

E. V. Rubanova, S. Piazolo, W. L. Griffin, S. Y. O'Reilly, "Deformation microstructures reveal a complex mantle history for polycrystalline diamond", Geochem. Geophys. Geosystems 13(10), 11 (2012). DOI: 10.1029/2012GC004250.

Y. Sano, R. Yokochi, K. Terada, M. L. Chaves, M. Ozima, "Ion microprobe $\mathrm{Pb}-\mathrm{Pb}$ dating of carbonado, polycrystalline diamond", Precambr. Res. 113(1-2), 155-168 (2002).

V. Sautter, J.-P. Lorand, P. Cordier, B. Rondeau, H. Lerou, C. Ferraris, S. Pont, "Petrogenesis of mineral micro-inclusions in an uncommon carbonado", Eur. J. Miner. 23(5), 721-729 (2011).

A. A. Shiryaev, K. Iakoubovskii, D. Grambole, N. D. Dubrovinskaia, "Spectroscopic study of defects and inclusions in bulk poly- and nanocrystalline diamond aggregates", J. Phys.: Cond. Matt. 18, L493-L501 (2006).

N. V. Sobolev, V. S. Shatsky, D. A. Zedgenizov, A. L. Ragozin, V. N. Reutsky, «Polycrystalline diamond aggregates from the Mir kimberlite pipe, Yakutia: Evidence for mantle metasomatism», Lithos 265, 257-266 (2016).

P. Soille, Morphological Image Analysis: Principles and Applications, Springer-Verlag, 1999, pp. 173-174.

Z. V. Spetsius, L. A. Taylor (2008) Diamonds of Yakutia: Photographic Evidence for their Origin. Tranquility Base Press, Lenior City, Tennessee, 278 pp.

I. Sunagawa (1984). Morphology of natural, synthetic diamond crystals. In: I. Sunagawa (Editor), Materials Science of the Earth's Interior. Terrapub, Tokyo, pp. 303-330.

S. V. Titkov; A. I. Gorshkov, S. F. Vinokurov; L. V. Bershov, D. I. Solodov, A. V. Sivtsov, "Geochemistry and genesis of carbonado from Yakutian diamond deposits", Geochem. Intern. 39(3), 228-236 (2001).

S. V. Titkov; A. I. Gorshkov, L. O. Magazina, A. V. Sivtsov, O. D. Zakharchenko, "Shapeless dark diamonds (yakutites) from the placers of the Siberian platform and criteria of their impact origin”, Geol. Ore Dep. 46(3), 191-201 (2004).

L. F. Trueb, W. C. Butterman, "Carbonado: a microstructural study”, Amer. Miner. 54(3-4), 412425 (1969).

A. P. Yelisseyev, V. P. Afanasiev, A. V. Panchenko, S. A. Gromilov, V. V. Kaichev, A. A. Saraev, "Yakutites: Are they impact diamonds from the Popigai crater?", Lithos 265, 278291 (2016).

D. A. Zedgenizov, B. Harte, V. S. Shatsky, A. A. Politov, G. M. Rylov, N. V. Sobolev, "Directional chemical variations in diamond showing octahedral following cuboid growth", Contrib. Miner. Petrol. 151(1), 45-57 (2006). 


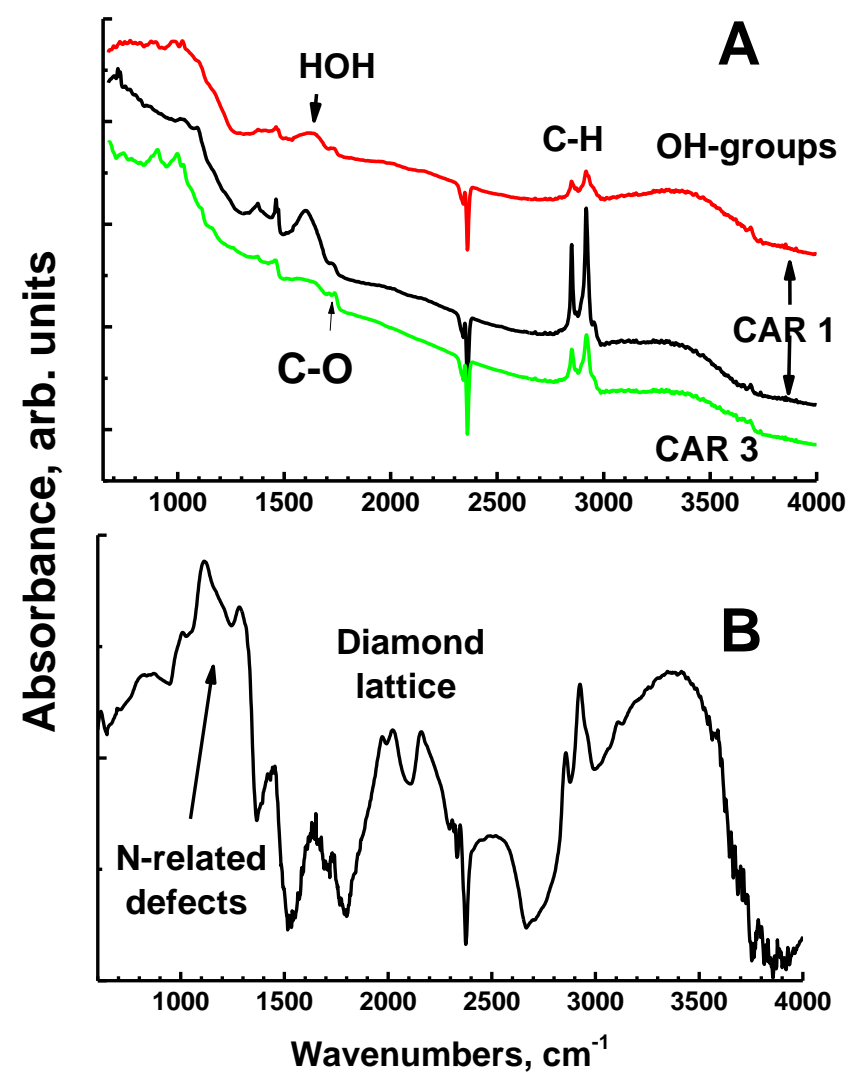

Fig. 1. FTIR spectra of carbonado samples CAR-1 and CAR-3 (A), and of cryptocrystalline diamond aggregate from Yakutian kimberlites (B). 

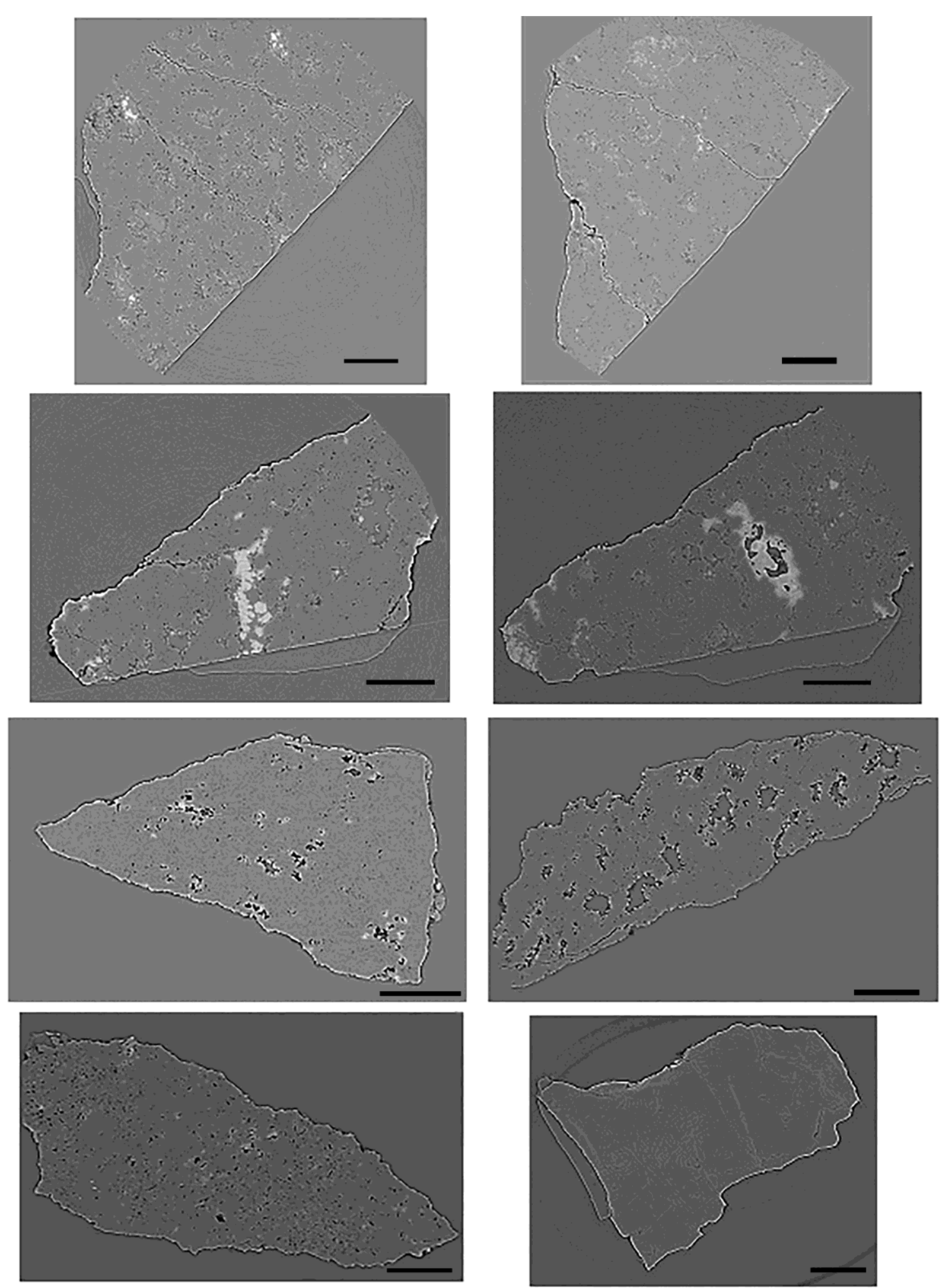

Fig. 2. Representative slices from phase tomography reconstructions for the studied samples.

Pixel size $0.7 \mu \mathrm{m}$, Scale bar corresponds to $200 \mu \mathrm{m}$. Bright areas are inclusions.

Top - CAR1, Second row: CAR2, Third row - diamondite 88 and 89, Bottom - diamondite 90 and yakutite. 


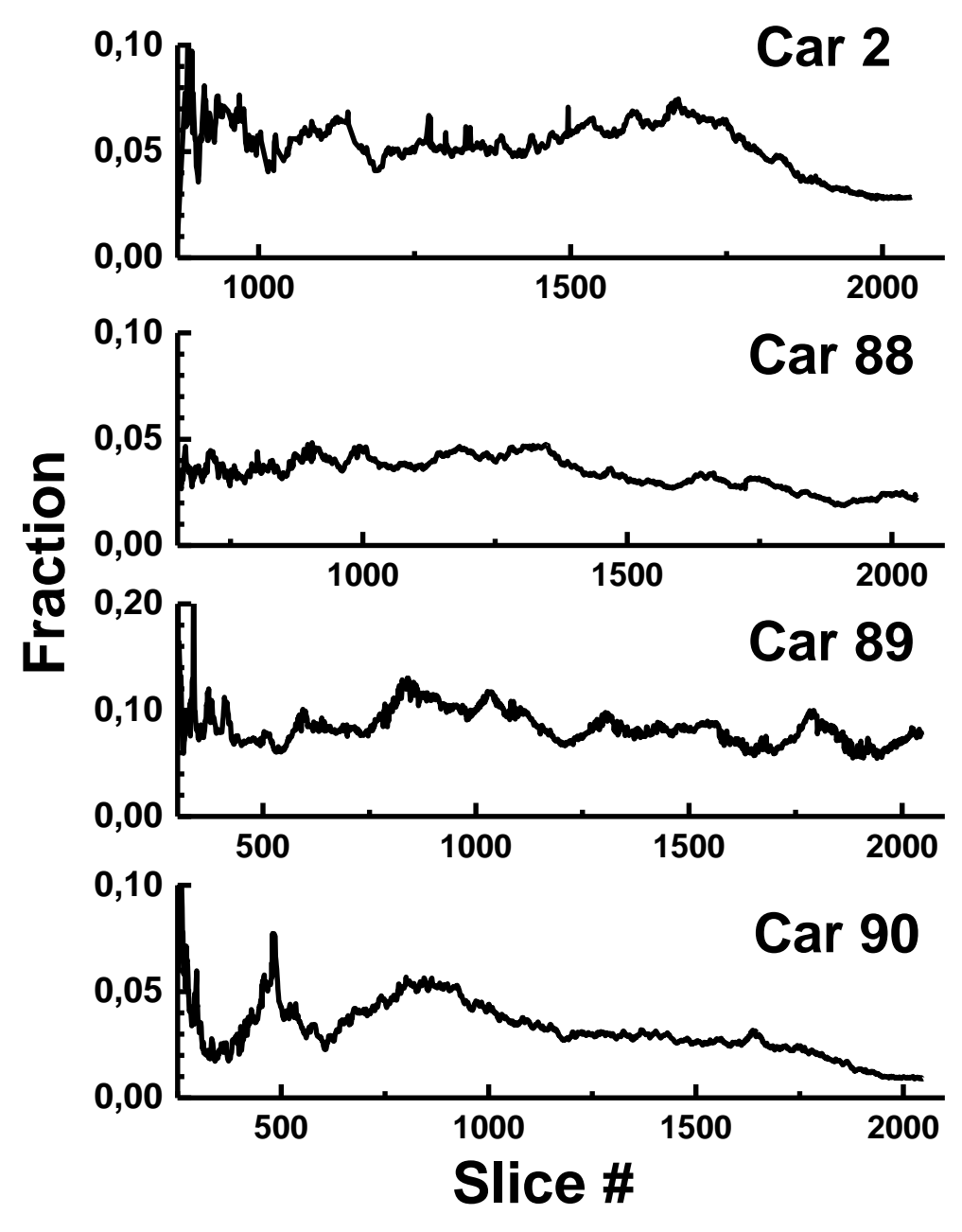

Fig. 3. Volume fraction of pores in a carbonado specimen (CAR-2) and in cryptocrystalline diamond aggregates from kimberlite. 

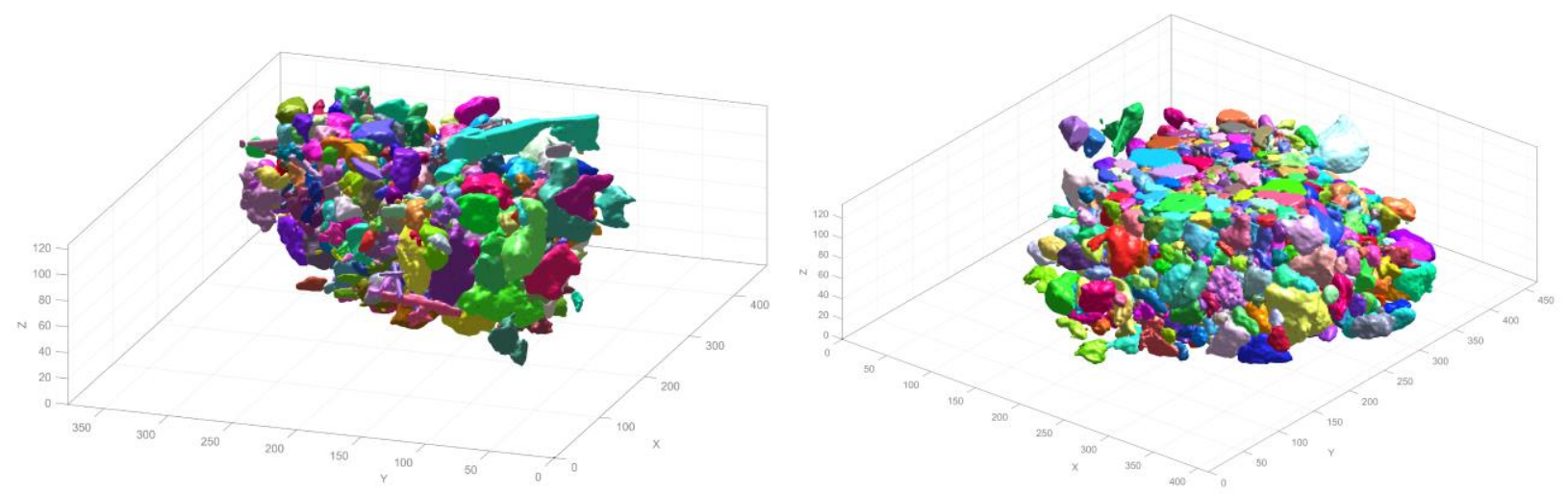

Fig. 4. 3D vizualisation of grains in samples CAR1 and CAR2 obtained from X-ray diffraction contrast tomography. Flat top surface reflects polished surface. 


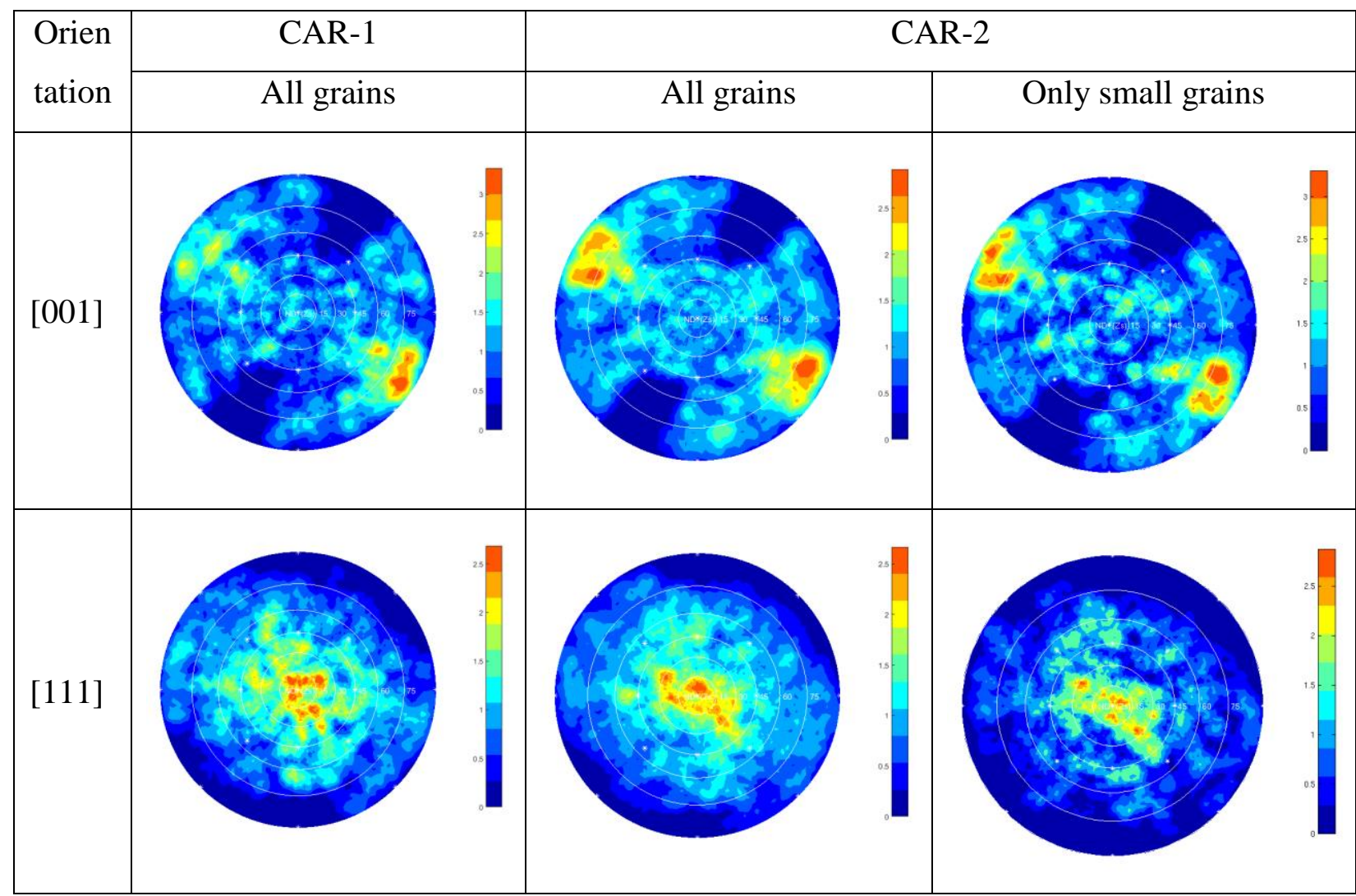

Fig. 5. Projections of Orientation Distribution Function (ODF) on different crystallographic planes for two carbonado samples 


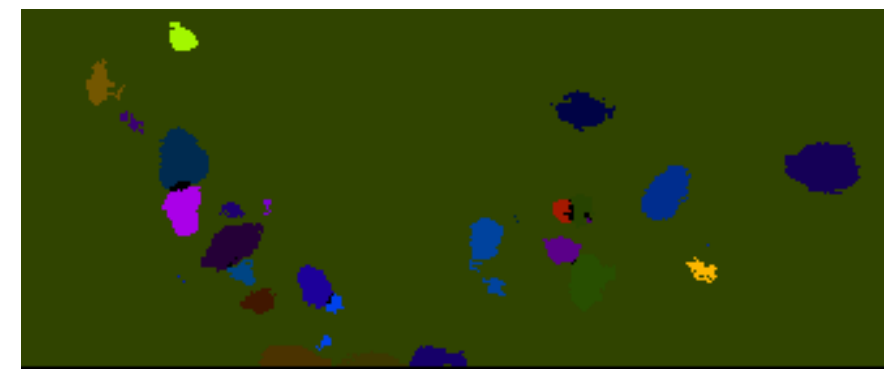

Fig. 6. A single slice through the grains shown in Fig. 4 showing relative spatial position of carbonado grains oriented in [110] direction $\left( \pm 15^{\circ}\right)$. 